\title{
Changes in Reported Nation-Level Pro-social Behavior Frequencies Over 6 Years: A Test of Alternative Predictors
}

\author{
Peter B. Smith ${ }^{1}$ (D) \\ Accepted: 13 December 2018 / Published online: 15 February 2019 \\ (C) The Author(s) 2019
}

\begin{abstract}
This research is designed to test alternative explanations for changes in national frequencies in reported pro-social behaviors. Representative samples drawn from 136 nations reported whether in the past month they had helped a stranger who needed help, donated money to a charity, and worked as a volunteer for an organization. Change in frequencies of these behaviors over a 6 year interval were examined in relation to changes in values and in social context. Increases were more frequent in more collectivist nations. Helping strangers increased most in nations where generalized trust decreased and demographic pressures became more acute. Donating increased where civility values rose and where problems associated with refugees and displaced persons increased. Working as a volunteer increased in nations where emancipative values became more widespread. Thus, measures of both values and contextual events are required to provide an adequate account for these types of change.
\end{abstract}

Keywords Pro-social behavior $\cdot$ Generalised trust $\cdot$ Fragile states index $\cdot$ Emancipative values

\section{Introduction}

In the continuing search for a better society there is a self-evident benefit in understanding the circumstances under which people are more likely to assist those in need to help. Prosocial behaviors are those that are undertaken to enhance or preserve the welfare of others (Piliavin et al. 1981). Research has typically focused on actions such as volunteering, donating blood or money, and helping those in distress (e.g., Batson et al. 2003; Lee et al. 1999). While considerable attention has been given to identifying variations in individuallevel predictors, such as motives and to the consequences of engaging in pro-social behavior (e.g., Weinstein and Ryan 2010), we know much less about factors affecting global variations in the frequency of pro-social behaviors. In a pioneering experimental study, Levine et al. (2001) showed marked variations across 23 nations in helping behaviors in response to simulated emergencies. However, the complexity of creating such a study and

Peter B. Smith

psmith@sussex.ac.uk

1 School of Psychology, University of Sussex, Falmer, Brighton BN1 9QG, UK 
the inevitable ambiguity as to whether the experimentation has been conducted in a similar manner in each context has meant that this initiative has not been further developed. We need alternative sources of data.

The circumstances obtaining within the broad range of national contexts around the world may well differentially elicit relevant motives and differing opportunities for prosocial actions than those that are found to prevail within the locations that have been most frequently examined. For instance, reasons given for working as an unpaid volunteer are found to vary between nations in terms of the interaction between the resources derived from national wealth and the demands of living with more extreme temperatures (van de Vliert et al. 2004a, b). Altruistic motives are more frequently reported from more favorable contexts, with self-serving motives more prevalent in less favorable contexts.

To better understand these variations, a first step is to obtain data on a fuller range of pro-social behaviors and the factors affecting them. A previous analysis drew on data provided by Gallup surveys of representative samples within 135 nations. Individuals within each sample reported on whether they had engaged in each of three pro-social behaviors during the past month (Smith 2015). In this study it was shown that self-reported frequencies of aiding strangers who needed help, donating money to charity and volunteering time to an organization were substantially correlated with one another, yielding an overall index of nation-level pro-social behavior. Scores on this index were compared with available characterizations of national differences devised and tested in recent decades by cross-cultural psychologists (Hofstede 1980, 2001; House et al. 2004; Schwartz 2004; Welzel 2010). The index was found to be best predicted by two nation-level measures of values, low ingroup favoritism (van de Vliert 2011) and low uncertainty avoidance (Hofstede 2001). These results were interpreted in terms of respondents' willingness to engage with persons outside their immediate group and to engage with the possible risks attendant upon doing so. Nation-level wealth was a significant predictor only of donating money. The relationships found between these various measures provided suggestive evidence as to the reasons why pro-social behaviors vary between nations. I further test these conclusions in the present study by examining changes in pro-social behavior frequencies over time.

\section{Reasons to Engage in Pro-social Behavior}

Eco-cultural theorists propose that frequencies of the particular patterns of behavior that are salient within a given cultural context will be a function of locally prevailing affordances and risks (Gelfand et al. 2011; Georgas et al. 2004). Changes in behaviors can be expected when values relevant to pro-social behavior become more adaptive, or when the incidence of risks changes. I first consider value change, leading toward the recent increase in emancipative values.

The index of in-group favoritism (van de Vliert 2011) that was found by Smith (2015) to be the strongest predictor of pro-social behavior is essentially a measure of collectivism, combining endorsement of family loyalty, nepotism and loyalty to one's nation. Collectivistic cultures have evolved in contexts that may be characterized in terms of distinctive climates, historic prevalence of pathogens and so forth (Fincher et al. 2008; van de Vliert 2011). In collectivist cultures, the predominant focus is upon one's interdependence with the key groups in which one holds membership (Hofstede 1980, 2001; Markus and Kitayama 2010; Schwartz 2004) and there is a significantly lower level of trust in persons from outside these groups (Allik and Realo 2004; Gheorghiu et al. 
2009; Realo et al. 2008). It is therefore plausible that pro-social behaviors toward strangers would be less frequent in nations whose culture is more collectivist. Within more individualistic cultures, greater emphasis is found on freedom to make one's personal choices and to accord equal rights to all (Schwartz 2004; Welzel 2013). Individualistic nations are found to score higher on generalized trust. Providing assistance to strangers is more directly in accord with these value priorities.

A series of analyses of responses to the successive waves of the representative national samples tapped by the World Values Survey has permitted the identification of a trend within many nations of the world over recent decades toward reduced collectivism and increased individualism (Inglehart 1997; Inglehart and Baker 2000; Inglehart et al. 2008; Inglehart and Oyserman 2004; Welzel 2013). Welzel (2013) defines this overall trend in terms of an increase in what he calls emancipative values. These values comprise endorsement of personal choice, equal rights for all, tolerance of diversity and preference for giving people more say at work and in public life. Nation-level factor analysis of responses to 12 survey items addressing these issues yields a single factor. Increase in the proportion of persons within a nation who endorse emancipative values is no doubt partly due to replacement of one generation by another, and partly to changes in wealth, education, and levels of employment. While the global trend toward endorsement of emancipative values is gradual, the effect of such changes should be reflected in increases in trust of strangers and in associated actions such as pro-social behaviors:

Hypothesis 1 Pro-social behavior frequencies will increase in nations where endorsement of emancipative values increases.

The second significant predictor of pro-social behavior identified by Smith (2015) was low uncertainty avoidance values (Hofstede 2001). In contrast to other measures of uncertainty avoidance (e.g., House et al. 2004), Hofstede's measure emphasizes the shunning of ambiguity and the search for structure and continuity. In contrast to recent increases in endorsement of emancipative values, no investigations have been reported as to change in endorsement of values relating to uncertainty avoidance. However, we know that a broad range of events in different societies do both increase and decrease specific risks over time. These include for instance the commencement and cessation of social unrest, wars, food emergencies, extreme weather and migration. Pro-social behaviors will be more hazardous in settings that are ambiguous or in which there are evident risks. The broad range of real and perceived risks faced by any particular individual are not readily identifiable, but nation-level risks that derive from these types of events can be more readily assessed. If values are a strong determinant of behavior, it follows that the trend in pro-social behavior frequencies will be upward in nations where identifiable risks are decreasing. However, it is also possible that the compelling nature of some emergencies may elicit helping behaviors despite the high level of risk associated with these behaviors. The second hypothesis assumes that this will occur less frequently than the more general tendency toward greater helping where risk is lowered:

Hypothesis 2 Pro-social behavior frequencies will increase in nations where identifiable risks decrease. 
The reasoning leading to the formulation of both Hypotheses 1 and 2 is built on the assumption that generalized trust will increase as emancipative values are adopted and as risks decline. This assumption can also be tested directly:

Hypothesis 3 Pro-social behavior frequencies will increase where generalized trust increases.

\section{Method}

The indices for pro-social behavior were based on the World Giving Index, using data provided by the Charities Aid Foundation, based in the UK (www.cafonline.org/publicatio ns/2017-publications/world-giving-index-2017.aspx). These data are taken from surveys of nationally representative samples conducted annually in up to 160 nations by the Gallup Organization, with a target sample of 1000 per nation. The exact survey question here employed is, During the past month have you done any of the following?- donated money to a charity?-volunteered your time to an organization?- - helped a stranger or someone you didn't know who needed help? Respondents answer yes or no to each of these items. Nation-level scores give the percentage of respondents responding yes. The single-item nature of these questions provides no further information as to any particular types of donation, of volunteering or of helping that respondents have in mind when answering. As a check on the validity of the index of pro-social behavior that he used, Smith (2015) computed correlations with relevant indices. Significant correlations were found with the national percentage of national gross income devoted to international aid, and with the national percentage of respondents to the World Values Survey reporting active membership of charitable organizations.

In order to estimate the degree of change in reported behaviors, the data from the reports published in 2010, 2011, 2016 and 2017 were accessed. Since each report is published 1 year after data collection, the sampled period extends from 2009 to 2016. To give a more reliable estimate of change, the data for 2010 and 2011 were averaged to yield a pre measure, with the averaged data for 2016 and 2017 giving a post measure. Change scores computed in this way were available for 136 nations. Cronbach alpha for the three prosocial behaviors was .53 , so it is preferable to test the hypotheses for each type of change separately, rather than computing an overall index of pro-social behavior change.

Five indices were used to test the hypotheses. Nation-level measures of emancipative values computed on the basis detailed by Welzel (2013) were taken directly from the website of the World Values Survey (www.worldvaluessurvey.org). Data were available from wave 5 for 36 nations and from wave 6 for 58 nations. Nations sampled in both waves 5 and 6 were 25, and these provided the necessary scores for increase in emancipative values. Through reference to all six waves of the World Values Survey, Welzel (2013) also provided evidence that the rate of increase in emancipative values differed between nations, but was relatively consistent over time for any particular nation. Using this logic, change scores were imputed for a further 42 nations for which there was data from either wave 5 or wave 6 and from one or more preceding waves. The imputed change score was calculated in proportion to the time interval between the score for wave 5 or 6 and the preceding score.

An alternative measure of value change is also drawn from a series of items within the World Values Survey in which respondents are asked which values should be emphasized 
in the socialization of children. Bond and Lun (2014) identified two nation-level factors which they named as self-directedness versus other-directedness and civility versus practicality. The first of these factors is named in a manner suggesting a relation to individualism versus collectivism, but the items defining it are quite different, and it is not included in this analysis. Civility versus practicality has greater potential relevance to pro-social behavior. In nations scoring high on civility parents emphasize development of tolerance and respect for other people and unselfishness in their children, whereas the qualities of thrift, saving money and things mark the practicality side of the dimension. Data for this dimension are available from wave 5 from 56 nations and from wave 6 from 60 nations, with 37 nations sampled at both times, yielding a change score for civility values.

The measure of identifiable risks was based on the Fragile States Index. This index is published annually by the Fund for Peace (www.fundforpeace.org). Scores for nations are based on content analysis of political, social and economic documents as well as expert ratings. Twelve sources of risk are each evaluated for 178 nations. These comprise demographic pressures, refugee flows, grievances between groups, loss of human capital through migration, inequality of development within the nation, economic decline, lack of government legitimacy, poor quality of public services, lack of human rights, threats to security, the presence of factionalization among the elite, and intervention from other nations. Scores from the 2010 index and the 2017 index were accessed, yielding change scores for 176 nations. The scales comprising the index show Cronbach alpha of .98 for 2010 and .97 for 2017, but alpha for the change scores shows low reliability, indicating differential occurrence of risky environments. Hypothesis 2 is therefore tested for each scale separately.

The measure of generalized trust comprised the national percentage of respondents agreeing with the statement, 'Most people can be trusted' rather than, 'You need to be careful in dealing with people'. Scores for each nation were taken from waves 5 and 6 of the World Values Survey. Data were available for 55 nations from wave 5 and 57 nations from wave 6.35 nations were sampled in both waves, yielding a change score expressed as the percentage endorsing generalized trust.

Additional measures for wealth and two dimensions of national culture were also included, in order to better understand the contexts in which change occurred. Wealth was measured as purchasing power parity for 2009 and for 2015 (World Development Report 2017). Change in national wealth between these dates was available for 127 nations. Since wealth is not normally distributed between nations but is negatively skewed, a logarithmic transformation to base 10 was employed. Scores for collectivism were taken from Hofstede (2001), with additional scores provided at www.geert-hofstede.com. A total of 86 scores were used, but the basis on which these scores were computed more recently by Hofstede and his colleagues has varied. In order to guard against the possibility that the more recent scores have less validity, analyses are reported for the full range of scores and also for his original data set of 50 nations.

On the basis of a 56 nation survey, Minkov and his colleagues have recently identified a new measure of individualism-collectivism, as well as a dimension of cultural variation named as monumentalism versus flexibility (Minkov and Hofstede 2012; Minkov et al. 2018). which approximates to the dimension named earlier by Hofstede (2001) as shortterm versus long-term orientation. The items defining monumentalism include willingness to help others. Scores for collectivism for 56 nations were taken from Minkov et al. (2017) and scores for monumentalism for 54 nations were taken from Minkov et al. (2018). The Minkov scores were included as they provide estimates of value endorsements that are contemporaneous with the pro-social behavior change data. 


\section{Results}

Before testing the hypotheses, it is necessary to establish the extent to which changes occurred in the frequency of reported pro-social behaviors over the 6 year period for which data are available. Table 1 indicates that there was a significant mean increase in helping of strangers from an average of $45 \%$ of respondents to an average of $50 \%$. There was no significant mean change in the frequency of donating money or working as a volunteer. However, there was substantial variation in mean reported frequencies, with standard deviations of 8.9 for helping strangers, 12.1 for donating money and 7.2 for volunteering. Table 1 also provides information on change over time in the frequency of the predictor variables. Emancipative values and wealth increased significantly, whereas civility and generalized trust did not. Among the fragile state indicators, eight showed significant improvement (represented by a decreased score), two showed significant deterioration and two showed no change.

Table 1 Mean change over time in reported pro-social behaviors and in predictors

\begin{tabular}{|c|c|c|c|c|}
\hline & $2010 / 2011$ & $2016 / 2017$ & Change & $\mathrm{t}$ \\
\hline \multicolumn{5}{|l|}{ Pro-social indices } \\
\hline Percent helping a stranger & 45.0 & 50.0 & +5.10 & $6.65 * * *$ \\
\hline Percent donating money & 29.4 & 30.9 & +1.50 & 1.64 \\
\hline Percent voluntary work & 20.2 & 21.2 & +1.01 & 1.44 \\
\hline \multicolumn{5}{|l|}{ Predictors } \\
\hline Emancipated values $2009-2014^{\mathrm{a}}$ & .470 & .496 & +.026 & $4.84 * * *$ \\
\hline Civility values $2009-2014^{\mathrm{b}}$ & .002 & -.021 & -.023 & 1.06 \\
\hline \multicolumn{5}{|l|}{ Fragile state index scores ${ }^{c}$} \\
\hline Demographic pressures & 6.18 & 5.46 & -.72 & $6.02 * * *$ \\
\hline Refugees and internally displaced persons & 5.07 & 6.27 & +1.21 & $7.84 * * *$ \\
\hline Group grievance & 5.98 & 6.32 & +.34 & $3.86^{* * *}$ \\
\hline Human flight and brain drain & 5.39 & 5.38 & -.01 & .02 \\
\hline Uneven economic development & 6.62 & 5.58 & -1.04 & $11.98 * * *$ \\
\hline Economic decline and poverty & 5.86 & 5.25 & -.61 & $6.02 * * *$ \\
\hline State legitimacy & 6.10 & 5.75 & -.35 & $4.29 * * *$ \\
\hline Public services & 5.59 & 5.22 & -.37 & $4.78 * * *$ \\
\hline Human rights and rule of law & 5.74 & 5.46 & -.29 & $3.54 * * *$ \\
\hline Security apparatus & 5.44 & 5.46 & +.02 & .12 \\
\hline Factionalized elites & 5.94 & 5.37 & -.56 & $3.27 * * *$ \\
\hline External intervention & 5.64 & 5.37 & -.07 & $3.11 * * *$ \\
\hline Generalized trust $2009-2014^{\mathrm{d}}$ & 25.65 & 25.95 & +0.30 & 0.22 \\
\hline Wealth (PPP) 2009-2015 & 14024.23 & $19,363.46$ & +5339.23 & $9.35^{* * *}$ \\
\hline
\end{tabular}

$* * p<0.01 ; * * * p<0.001$

${ }^{a}$ scores for emancipated values are standard scores based on Welzel's (2013) factor analysis

b scores for civility values are standard scores based on Bond and Lun's (2014) factor analysis

${ }^{\mathrm{c}}$ fragile states indices range from 1 to 10 . Higher scores indicate increased fragility

dpercent of persons agreeing that 'most people can be trusted'

e purchasing power parity index of US dollars income per annum 
Table 2 Correlations of descriptors with increased pro-social behaviors

\begin{tabular}{lcccc}
\hline Nation-level descriptors & $\mathrm{N}$ & Increased helping & $\begin{array}{c}\text { Increased } \\
\text { donating }\end{array}$ & $\begin{array}{l}\text { Increased } \\
\text { volunteering }\end{array}$ \\
\hline Hofstede collectivism & 86 & $.39 * *$ & .15 & $.21^{* *}$ \\
Hofstede collectivism (1980 scores) & 50 & $.46^{* *}$ & .19 & .23 \\
Minkov collectivism & 52 & $.25 \dagger$ & $.24 \dagger$ & $.30^{*}$ \\
Bond civility values & 54 & .07 & -.15 & $.31^{*}$ \\
Minkov Monumentalism & 52 & -.13 & -.05 & -21 \\
PPP2015log & 134 & -.02 & -.05 & .07 \\
Fragile state 2017 & 132 & .05 & .08 & -.06 \\
Generalised trust 2014 & 53 & -.18 & .07 & .00 \\
\hline
\end{tabular}

$\dagger p<0.10 ; * p<0.05 ; * * p<0.01$

Table 3 Changes over time by type of nation

\begin{tabular}{llllr}
\hline & $2010 / 2011$ & $2016 / 2017$ & Change & $\mathrm{t}$ \\
\hline Individualistic nations (N=34) & & & +1.4 & 1.43 \\
Percent helping a stranger & 46.5 & 47.9 & -3.2 & -1.28 \\
Percent donating money & 46.4 & 43.2 & +1.0 & 1.29 \\
Percent voluntary work & 23.1 & 24.1 & +8.9 & $7.31^{* * *}$ \\
Collectivistic nations (N=52) & & & +2.2 & 1.51 \\
Percent helping a stranger & 45.3 & 54.2 & +3.5 & $3.58^{* * *}$ \\
Percent donating money & 27.6 & 29.8 & & $2.74^{* *}$ \\
Percent voluntary work & 18.0 & 21.5 & +3.7 & $2.38^{*}$ \\
Unclassified nations (N=50) & & 47.2 & +4.0 & 1.30 \\
Percent helping a stranger & 43.5 & 23.6 & -0.5 & \\
Percent donating money & 19.6 & 19.0 & & \\
Percent voluntary work & 20.5 & & & \\
\hline
\end{tabular}

$* p<0.05 ; * * p<0.01 ; * * * p<0.001$

Having established a unidirectional change in one form of pro-social behavior and some evidence for variability in the others, it is next useful to consider whether it is possible to characterize the contexts in which increases occurred. Table 2 shows a tendency for increased pro-social behaviors to occur in nations that are collectivistic, rather than individualistic. This trend is found whether one employs the scores derived from Hofstede's original survey or from the recent scores reported by Minkov et al. (2017). Volunteering increases also in nations scoring high on civility. However, there is no association between increases and levels of monumentalism, national wealth, generalised trust, or state fragility.

The effect for collectivism is marked, but even when correlating change scores with the full range of Hofstede scores, there remain 50 of the 136 nations in the sample for whom no Hofstede scores are available, with 21 of these located in Africa. Table 3 compares change scores for nations scoring above and below the sample mean for Hofstede collectivism, and those for which there is no score. Since many of the unclassified nations are also likely to be collectivistic, it is evident that the more individualistic nations are distinctive in showing no mean changes. The contrasts between these sets of 
nations in the types of change that do and do not occur indicate that it can be valuable to examine the correlates of change for each section as well as for the overall sample.

Tests of the hypotheses are provided by the correlations shown in Table 4. Hypothesis 1 is tested using the measures of emancipated values and civility. Hypothesis 2 is tested in relation to the twelve component indices of the fragile states index. No specific expectations were formulated as to which of these components would be distinctively relevant to change in pro-social behavior. Hypothesis 3 is tested using the measure of generalized trust. Since the results differ substantially for each of the three types of prosocial behavior, they are considered in turn.

\subsection{Helping}

The helping of strangers rose globally, but none of the three hypotheses concerning its incidence received significant empirical support. There are trends toward increased helping where civility values increase, and in contexts of economic decline and where external intervention is reduced. Table 4 also shows a significant negative correlation between an increase in generalized trust and increased helping of strangers. This is the reverse of the effect predicted by Hypothesis 3.

Table 4 Correlations of predictors with increased pro-social behaviors

\begin{tabular}{lccc}
\hline Predictors & Increased helping & Increased donating & $\begin{array}{c}\text { Increased } \\
\text { volunteer- } \\
\text { ing }\end{array}$ \\
\hline Emancipated values increase 2009-2014 $(\mathrm{N}=24)$ & .06 & $-.40^{*}$ & $.44^{*}$ \\
Emancipated values increase (imputed) $(\mathrm{N}=67)$ & .06 & -.19 & $.35^{* *}$ \\
Civility values increase 2009-2014 $(\mathrm{N}=35)$ & $.29 \dagger$ & $.39 *$ & .14 \\
Fragile state index improved scores $(\mathrm{N}=132)$ & & & .07 \\
Demographic pressures & & -.01 & $.19 *$ \\
Refugees and internally displaced persons & -.01 & -.14 & -.03 \\
Group grievance & .01 & .03 & .08 \\
Human flight and brain drain & .14 & .05 & .05 \\
Uneven economic development & .00 & .13 & $-.15 \dagger$ \\
Economic decline and poverty & $-.15 \dagger$ & .10 & $.24^{* *}$ \\
State legitimacy & .05 & .02 & -.11 \\
Public services & .01 & .09 & .05 \\
Human rights and rule of law & .05 & .07 & -.15 \\
Security apparatus & -.04 & .14 & -.10 \\
Factionalized elites & .07 & $.21 *$ & -.01 \\
External intervention & $.16 \dagger$ & .14 & -.18 \\
Generalized trust increase 2009-2014 $(\mathrm{N}=31)$ & $-.39 * *$ & -.13 & -.01 \\
Wealth increase 2009-2015 (N=127) & .03 & & \\
\hline
\end{tabular}

$\dagger p<0.10 ; * p<0.05 ; * * p<0.01$ 


\subsection{Donating}

Hypothesis 1 receives support in relation to increased civility values, but across the 24 nation sample it is significantly reversed in relation to increased emancipative values. When the broader sample of nations using the imputed measure of emancipated values is employed, this effect is no longer significant. Hypothesis 2 is supported in relation to more frequent donation of money where there is reduced factionalization of national elites. There is no support for Hypothesis 3.

\subsection{Volunteering}

Hypothesis 1 is supported in relation to increase in emancipative values across the 24 nations for which change data are available. This result is sustained when the broader sample of nations using the imputed measure of emancipated values is employed. Supporting Hypothesis 2, Table 4 also shows that increased volunteering is significantly associated with reduced tensions associated with refugees and internal displacement and with enhanced acceptance of state legitimacy. There is also a tendency for increased volunteering where there is economic decline. There is again no support for Hypothesis 3.

Finally, although no prediction was made in relation to wealth, Table 4 shows that there is no relation between increased national wealth and change in any of the pro-social behaviors.

\section{Discussion}

Across the 6 year period for which data are available, national levels of helping strangers increased, whereas donating money and volunteering did not. However, the data indicated an upward trend in each pro-social behavior within more collectivist cultures. Although Smith (2015) found that the frequency of the three behaviors across nations was strongly associated, it appears that changes in these frequencies are less strongly associated. I first discuss the results for each pro-social behavior in turn.

\subsection{Helping}

Neither values not the fragile states index proved significant in explaining increased helping. The significantly reversed result relating increased helping in relation to decreased generalized trust may give some indication of an alternative explanation. The measure of generalized trust is a single item measure, and the correlation is based on only 31 nations, so some caution is required in interpreting the meaning and reliability of this finding. However, Smith (2015) found that this one-item measure correlated at .58 with Welzel's (2010), 6-item measure of trust over 78 nations. Within nation-level data, there is no reason to expect that the individuals who help others are necessarily the same persons as those who record decreasing generalized trust. Helping and growing distrust may be concomitants of distinctive nation-level events, particularly in the context of instability or social conflict. Table 3 shows that increased helping was strongest in collectivist nations. Within this subsample, increased helping correlated significantly with deterioration in the fragile states index for demographic pressures $(\mathrm{r}=-.39 ; p<.05)$. Within the overall sample, the trends in the fragile states indices associated with increased helping were economic decline and 
reduced aid. These types of increasing adversity may be the ones that most readily elicit both decreased generalized trust among the many and peer assistance by the few to those in evident distress. Nations showing particularly marked increases in helping included Iraq, Jordan, Pakistan and Kosovo.

\subsection{Donating}

The values predictors showed significant but inconsistent effects in relation to donating. Evidently civility values are more relevant to increased donating than are emancipative values. The number of nations yielding the reversed effect for emancipative values is only 24 and the effect is not sustained when using the imputed measure across 67 nations. The significantly reversed effect could therefore reflect an issue that is distinctive to the 24 nations. In a subsidiary analysis selecting data only for these nations, donating is significantly predicted by the fragile states index for worsening of problems associated with refugees and displaced persons $(\mathrm{r}=-.46 ; p<.05)$. Selecting 67 nations, even though the correlation of increased donating with emancipative values is no longer significant, its relation with worsening of refugee problems remains significant $(\mathrm{r}=-.28 ; p<.05)$. As Table 3 indicated, mean donating increased significantly only in the unclassified nations, where donation frequencies were initially much lower, and there was very little data on value changes from these nations. It is likely that donating in these contexts is also more responsive to events and emergencies rather than to values, but the data give no definitive indication as to the specific emergencies that may have been salient. The greatest increases in donating were in Myanmar, Indonesia and several Central Asian republics. Thus, both value changes and specific events may be entailed in changes in donating.

\subsection{Volunteering}

Support for both Hypotheses 1 and 2 was strongest in relation to increased volunteering. This suggests that some aspects of changes in volunteering are relatively similar across samples, while other aspects are more dependent upon the specific local circumstances. The distinction made by van de Vliert et al. (2004a, b) between altruistic and self-serving reasons for volunteering may be relevant here. These authors found that the balance between these motives varied between well-resourced and poorly-resourced nations. Values and contexts may interact to elicit volunteering for differing reasons.

\subsection{Comparison of behaviors}

The fact that different results were obtained for the three types of pro-social behavior change is consistent with the prior literature conducted at the individual level of analysis. For instance, Lee et al. (1999) found that volunteering was more responsive to the expectations of others than were donations of money or of blood. At the nation-level, awareness of the values of others is a likely basis for inferring what volunteering might incur social approval. Lee et al. found donation of money more strongly predicted by persons' own past experience of their parents' reported behaviors. In the present findings, both donating and helping frequencies appear to have been more contingent on circumstance, but at this level of analysis we have no information on the attributes of those individuals who are most responsive to changing circumstances. The fragile states index yielded relatively few 
significant effects, perhaps because most of the indices are summarized at a level that does not spell out the types of voluntary actions that individuals might feel induced to take. The index for refugee flows and internal displacement is the one that does have a more immediate implication, and this was the one showing one of the two strongest effects.

\subsection{Generalized trust}

In formulating the hypotheses, it was proposed that increases in generalized trust would be associated with increased emancipative values and reduced environmental risks, and would thus also be linked with increases in pro-social behaviors. No evidence was found in support of this postulate. Even where value changes are found to be predictive, for instance in relation to increased volunteering, there is no associated effect for generalized trust. In order to consider alternative reasons for this pattern of results, it is important to consider that these data refer to nations, not to individuals. Within a given nation, persons whose emancipative values are increasing may not be the same persons whose generalized trust is increasing. Furthermore, those whose changed values encourage them to volunteer might do so in contexts where distrust is prevalent, or where it is not. The negative relation found between helping and generalized trust is consistent with this possibility. Pro-social behaviors may be particularly enhanced in circumstances where there is an interaction between emancipative value change and the types of challenging situation that are tapped by the fragile states index.

\subsection{Limitations and Future Directions}

Across the time period surveyed, the changes in reported pro-social behaviors were modest, compared to pre-existing contrasts in their frequency between nations. Responses to the survey questions provide no information as to the nature and extent of the behaviors in which respondents engaged, nor is there any certainty of uniform understandings of what exactly is or is not volunteer behavior (Handy et al. 2000). In addition, there is no control over socially desirable responding. However, these issues are less problematic when examining change over time, since sources of error in each nation are likely to be relatively constant.

As in studies of this type that rely heavily on secondary analyses, the nations that have been sampled frequently do not overlap with one another, thereby constraining the potential for hypothesis testing. This is particularly problematic for any study addressing change, since it requires sampling overlap at two separate points in time. Nonetheless, the samples from which the present conclusions are drawn greatly exceed the extent of those used in the pioneering study of Levine et al. (2001).

Since all reported analyses are correlational, it is not possible to know whether the associations found between predictors and change imply causation, or whether they indicate covariation in response to events and developments within particular nations. One way to address this ambiguity would be to compare the correlations between Time 1 predictors and Time 2 pro-social behaviors with the correlations between Time 2 predictors and Time 1 pro-social behaviors. Unfortunately this is not meaningful in the present dataset as the countries sampled at Times 1 and 2 are not always identical. At least in relation to donating, we do have some evidence that increased donating may have causal effects. Aknin et al. (2013) showed that across 136 nations, those who donated reported greater happiness than those who did not. Across four contrasting nations, they then used experimental 
methods to show that those assigned to recall making a donation to others showed greater happiness than those assigned to recall spending money on themselves.

The fragile states indices provided the best available data as to relevant environmental risks. In future studies it may be preferable to distinguish the general trend toward enhanced pro-social behaviors that is associated with increases in emancipated values from more specific effects attributable to risks in the nations within which they are particularly salient. This could be useful for instance in contexts where refugee presence, economic decline or loss of security are substantive issues. As individuals may also respond to perceived risks in a variety of ways, future studies in which indices that access responses to risk more directly may prove beneficial. The results suggest that changes in generalized trust may provide one such indicator.

\section{Conclusions}

This study extends the conclusions drawn by Smith (2015) in two ways. Firstly, it indicates that measures derived from the concept of collectivism not only predict the incidence of pro-social behavior at a given point in time, but are also predictive of increases over time. This is consistent with the portrayal of the global value changes identified by Welzel (2013) as responsive to a multitude of contemporary technological, educational and political changes.

Secondly, the study provides evidence that changes in the incidence of different prosocial behaviors are also responsive to changes in local context. As Lee et al. (1999) also found, the factors affecting the occurrence of pro-social behaviors differ, depending upon their public visibility. Volunteering was the most visible behavior examined in their study and they found it to be more dependent on the expectations of others than the other pro-social behaviors that they considered. Volunteering is also the most visible and the most socially engaged with others over time of the three behaviors in the present study, and its increase was found to be related to the increased prevalence of emancipative values. Within nation-level data we do not know whether individual volunteers themselves endorsed emancipative values, only that they acted within a context in which such values were increasingly prevalent.

Donation and helping of strangers are less publicly visible behaviors. Increased donation is shown to be best explained by increased civility values and by increasing salience of problems relating to refugees and displaced persons, although these effects are independent of one another, occurring within different subsets of the overall data. Increased helping is particularly associated with increased demographic pressures among more collectivistic nations. Thus both value change and contextual events can aid understanding of changing national pro-social behavior frequencies. Fuller explanation of the contrasting effects for volunteering versus those for donating and helping will require the availability of a broader range of data for changes in generalized trust and in emancipative values. For the present, we know that the large differences in pro-social behaviors across nations are relatively stable, but that we can identify some of the value changes and circumstances relevant to their enhancement.

OpenAccess This article is distributed under the terms of the Creative Commons Attribution 4.0 International License (http://creativecommons.org/licenses/by/4.0/), which permits unrestricted use, distribution, and reproduction in any medium, provided you give appropriate credit to the original author(s) and the source, provide a link to the Creative Commons license, and indicate if changes were made. 


\section{References}

Aknin, L. B., Barrington-Leigh, C. P., et al. (2013). Prosocial spending and well-being: Cross-cultural evidence for a psychological universal. Journal of Personality and Social Psychology, 104(4), 635-652.

Allik, J., \& Realo, A. (2004). Individualism-collectivism and social capital. Journal of Cross-Cultural Psychology, 35(1), 29-49.

Batson, C. D., van Lange, P., et al. (2003). Altruism and helping behavior. In M. A. Hogg \& J. Cooper (Eds.), Sage handbook of social psychology (pp. 279-295). London: Sage.

Bond, M. H., \& Lun, V. (2014). Citizen-making: The role of national goals for socializing children. Social Science Research, 44(1), 75-85.

Fincher, C., Thornhill, R., et al. (2008). Pathogen prevalence predicts human cross-cultural variability in individualism/collectivism. Proceedings of the Royal Society B: Biological Sciences, 275(1640), 1279-1285.

Gelfand, M. J., Raver, J. L., et al. (2011). Differences between tight and loose cultures: A 33 nation study. Science, 332(27), 1100-1104.

Georgas, J., van de Vijver, F., et al. (2004). The ecocultural framework, ecosocial indices and psychological variables in cross-cultural research. Journal of Cross-Cultural Psychology, 35(1), 74-96.

Gheorghiu, M., Vignoles, V. L., et al. (2009). Beyond the United States and Japan: Testing Yamagishi's emancipation theory of trust across 31 nations. Social Psychology Quarterly, 72(4), 365-383.

Handy, F., Cnaan, R. A., et al. (2000). Public perception of who is a volunteer: An examination of the netcost approach from a cross-cultural perspective. VOLUNTAS: International Journal of Voluntary and Nonprofit Organizations, 11(1), 45-65.

Hofstede, G. (1980). Culture's consequences: International differences in work-related values. Beverly Hills: Sage.

Hofstede, G. (2001). Culture's consequences: Comparing values, behaviors, institutions and organizations across nations. Thousand Oaks: Sage.

House, R. J., Hanges, P. J., et al. (2004). Leadership, culture and organizations: The GLOBE study of 62 nations. Thousand Oaks: Sage.

Inglehart, R. (1997). Modernization and post-modernization: Cultural, economic and political change in 43 nations. Princeton: Princeton University Press.

Inglehart, R., \& Baker, W. E. (2000). Modernization, cultural change and the persistence of traditional values. American Sociological Review, 65, 19-51.

Inglehart, R., Foa, R., Peterson, C., \& Welzel, C. (2008). Development, freedom and rising happiness: A global perspective (1981-2007). Perspectives on Psychological Science, 3, 264-285.

Inglehart, R., \& Oyserman, D. (2004). Individualism, autonomy and self-expression: The human development syndrome. In H. Vinken, J. Soeters, \& P. Ester (Eds.), Comparing cultures: Dimensions of culture in a comparative perspective (pp. 74-96). Leiden: Brill.

Lee, L., Piliavin, J. A., et al. (1999). Giving time, money and blood: Similarities and differences. Social Psychology Quarterly, 62(3), 276-290.

Levine, R. V., Norenzayan, A., \& Philbrick, K. (2001). Cross-cultural differences in helping strangers. Journal of Cross-Cultural Psychology, 32(5), 543-560.

Markus, H. R., \& Kitayama, S. (2010). Cultures and selves. Perspectives on Psychological Science, 5(4), 420-430.

Minkov, M., Bond, M. H., et al. (2018). A Reconsideration of Hofstede's fifth dimension: New flexibility versus monumentalism data from 54 nations. Cross-Cultural Research, 52(3), 309-333. https://doi. org/10.1177/1069397117727488.

Minkov, M., Dutt, P., et al. (2017). A revision of Hofstede's individualism-collectivism dimension: A new national index from a 56 country study. Cross-Cultural and Strategic Management, 24(3), 386-404.

Minkov, M., \& Hofstede, G. (2012). Hofstede's fifth dimension: New evidence from the world values survey. Journal of Cross-Cultural Psychology, 43(1), 3-14.

Piliavin, J. A., Dovidio, J. F., et al. (1981). Emergency intervention. New York: Academic Press.

Realo, A., Allik, J., et al. (2008). Radius of trust: Social capital in relation to familism and institutional collectivism. Journal of Cross-Cultural Psychology, 39(4), 447-462.

Schwartz, S. H. (2004). Mapping and interpreting cultural differences around the world. In H. Vinken, J. Soeters, \& P. Ester (Eds.), Comparing cultures: Dimensions of culture in a comparative perspective (pp. 43-73). Leiden: Brill.

Smith, P. B. (2015). To lend helping hands: In-group favoritism, uncertainty avoidance and the national frequency of pro-social behaviors. Journal of Cross-Cultural Psychology, 46(6), 759-771.

Van de Vliert, E. (2011). Climato-economic origins of variation in in-group favoritism. Journal of CrossCultural Psychology, 42(3), 494-515. 
Van de Vliert, E., Huang, X., \& Levine, R. V. (2004a). National wealth and thermal climate as predictors of motives for volunteer work. Journal of Cross-Cultural Psychology, 35(1), 62-71.

Van de Vliert, E., Huang, X., \& Parker, P. M. (2004b). Do colder and hotter climates make richer societies more, but poorer societies less, happy and altruistic? Journal of Environmental Psychology, 24(1), 17-30.

Weinstein, N., \& Ryan, R. M. (2010). When helping helps: Autonomous motivation for pro-social behavior and its influence on well-being for the helper and recipient. Journal of Personality and Social Psychology, 98(2), 222-244.

Welzel, C. (2010). How selfish are self-expression values? A civicness test. Journal of Cross-Cultural Psychology, 41(2), 152-174.

Welzel, C. (2013). Freedom rising: Human empowerment and the quest for emancipation. New York: Cambridge University Press.

World Development Report (2017). https://wdi.worldbank.org/tables/data-catalog/world-development-indic ators. Accessed April 26, 2018.

Publisher's Note Springer Nature remains neutral with regard to jurisdictional claims in published maps and institutional affiliations. 